\title{
Recurrent and residual juvenile angiofibromas
}

\author{
I TYAGI, R SyAL, A GOYAL
}

\begin{abstract}
Introduction: In the surgical management of juvenile nasopharyngeal angiofibromas the possibility of recurrences and residual tumours is always there. This study was undertaken to predict the prognostic factors determining recurrence of juvenile nasopharyngeal angiofibroma and to find out the usual sites of these tumours.

Material and methods: The medical records of 95 patients with histologically proven juvenile nasopharyngeal angiofibroma were reviewed retrospectively. The commonest surgical approach used was a combined transpalatal and transmaxillary approach with a lazy $\mathrm{S}$ incision. A conservative lateral infratemporal approach was used in three cases.

Results: Complete removal of the juvenile nasopharyngeal angiofibroma was achieved in 78 (82 per cent) of the cases in a single operation. A residual tumour was found in 17 (18 per cent) cases and recurrences occurred in 13 (13.7 per cent) cases.

Conclusions: Extensions into the pterygoid fossa and basisphenoid, erosion of the clivus, intracranial extensions medial to the cavernous sinus, invasion of the sphenoid diploe through a widened pterygoid canal, feeders from the internal carotid artery, a young age and a residual tumour were risk factors found associated with recurrence of juvenile nasopharyngeal angiofibroma.
\end{abstract}

Key words: Angiofibroma, Child; Nasopharynx, Recurrence; Otorhinolaryngological Surgical Procedures

\section{Introduction}

Juvenile nasopharyngeal angiofibroma is a histologically benign yet locally aggressive vascular tumour. It is considered to be the most common benign neoplasm of the nasopharynx accounting for 0.05 per cent of head and neck tumours. ${ }^{1}$ The highest incidence is found in India and Egypt. It commonly affects young pubescent males. Juvenile nasopharyngeal angiofibroma usually originates from the region of the sphenopalatine foramen just posterior to the middle turbinate. ${ }^{2}$ Although benign, the tumour causes pressure erosion of the bones and exhibits submucosal spread. Surgery has been the overwhelming choice for primary treatment of juvenile nasopharyngeal angiofibroma and the selection of proper approaches depends primarily upon the extensions of the tumour. The surgical management of juvenile nasopharyngeal angiofibroma is complicated by tumour vascularity, pattern of vascular supply, young age of patients, difficult surgical access, and complex loco regional anatomy. As a result the possibility of incomplete removal of the angiofibroma is always there. Recurrence is the other conspicuous feature of the natural history of juvenile nasopharyngeal angiofibroma. The situation was summed up accurately by Lafargue ${ }^{3}$ that some angiofibromas do not recur while others operated on by the same method recur with astonishing rapidity. This study was undertaken to help predict the prognostic factors determining recurrence of juvenile nasopharyngeal angiofibroma and to find out the usual sites of these tumours.

\section{Material and methods}

The medical records of patients with histologically proven large juvenile angiofibroma who received treatment in our institution between 1992 and 2002 were reviewed retrospectively. Fisch's ${ }^{4}$ (1983) staging of juvenile nasopharyngeal angiofibroma, revised by Andrews et al. ${ }^{5}$ in 1989 , with a few modifications (large extradural extensions of juvenile nasopharyngeal angiofibroma were included in stage IVa) was used for classification in this study (Table I). As our institute is a referral centre the majority of cases operated on were in stage III and IV as shown in Table II. Stage I juvenile nasopharyngeal angiofibroma were not included in this study. A battery of investigations like contrast enhanced computed tomography (CT) scan, magnetic resonance imaging (MRI) (in cases with intracranial extensions) and angiography (selected cases only) were reviewed retrospectively in patients in

From the Neuro-otology Unit, Department of Neuro-surgery, Sarjay Gandhi Post Graduate Institute of Medical Sciences, Lucknow, India.

Accepted for publication: 17 October 2006. 
TABLE I

ANDREWS' STAGING OF ANGIOFIBROMA

\begin{tabular}{ll}
\hline Stage & Characteristics \\
\hline I & $\begin{array}{c}\text { Tumour limited to the nasal cavity and } \\
\text { nasopharynx } \\
\text { Extensions into pterygopalatine fossa, } \\
\text { maxillary, sphenoid, ethmoid sinuses }\end{array}$ \\
IIIa & $\begin{array}{c}\text { Extensions into orbit or infratemporal } \\
\text { fossa without intracranial extensions }\end{array}$ \\
IIIb & $\begin{array}{c}\text { Stage IIIa with small extradural } \\
\text { intracranial (parasellar) involvement }\end{array}$ \\
IVa & $\begin{array}{c}\text { Large extradural intracranial or } \\
\text { intradural extensions }\end{array}$ \\
IVb & $\begin{array}{c}\text { Involvement of the cavernous sinus, } \\
\text { pituitary, or optic chiasm }\end{array}$
\end{tabular}

the study group. Pre-operative embolisation of feeding vessels and the tumour bed by polyvinyl alcohol particles was performed in 25 cases.

A transpalatal surgical approach was used in 15 cases of stage II juvenile nasopharyngeal angiofibroma. Stage IIIa juvenile nasopharyngeal angiofibroma having infratemporal, pterygopalatine and orbital extensions in 62 cases were removed in this case series by combining a transpalatal and transmaxillary approach with a lazy $\mathrm{S}$ incision, only in three cases of stage IIIa where the angiofibroma was extending up to the temporal fossa, was a conservative lateral infratemporal approach (type D1 approach) used. Small intracranial extensions of juvenile nasopharyngeal angiofibroma, that is stage IIIb tumours, were removed along with extra cranial part in 10 cases. Defects in the bone through which the intracranial extensions had occurred were widened. Just by performing a blunt dissection and applying gentle traction, intracranial extensions were separated from the dura. Intracranial pressure was kept low by giving mannitol during this procedure. Even stage IVa juvenile nasopharyngeal angiofibromas were removed by this approach in two cases. Staged frontotemporal craniotomy was performed to remove residual tumours in five cases with stage IVa tumours. A post-operative contrast enhanced CT scan was taken six weeks after surgery in all cases. Cases with a minimum follow up of two years were included in this study.

\section{Results}

Complete removal of juvenile nasopharyngeal angiofibromas was achieved in 78 (82 per cent) of cases in a single operation. Residual tumours were found in 17 (18 per cent) cases at the first post-operative CT scan six weeks after surgery. Residual tumours were found in the region of the temporal and infratemporal fossa in four cases (23.5 per cent), in the region of the sphenoid sinus, base of the pterygoids, clivus and vidian canal in five cases (29.4 per cent), the medial aspect of the cavernous sinus in three cases (17.6 per cent) and large residual intracranial extensions were present in the remaining five cases (29.4 per cent).

A second operation was performed to remove the residual tumour in 14 (82 per cent) cases. In the remaining three cases residual tumours were present in the region of the cavernous sinus which was followed subsequently. These residual tumours either involuted or did not grow in size.

Recurrences occurred in 13 (13.7 per cent) cases in spite of complete removal. In four cases, three to four operations were performed to remove recurrences. Incidence of recurrent and residual tumours by stage is shown in Table III.

\section{Discussion}

In this case series the incidence of residual angiofibromas was 18 per cent while recurrences occurred in 13.7 per cent of cases. These results are good when compared to other studies $^{6}$ as shown in Table IV. Risk factors found associated with recurrence of juvenile nasopharyngeal angiofibromas were extensions into the pterygoid fossa and basisphenoid, invasion of the sphenoid diploe through a widened pterygoid canal (Figure 1a), intracranial extensions medial to the cavernous sinus (Figure 1b), erosion of the clivus (Figure 1c), feeders from the internal carotid artery (Figure 1d), a young age and an evident residual tumour. Preoperative embolisation was not found to be associated with an increased incidence of residual and recurrent tumours. The majority of recurrences occurred within six months of the first operation.

\section{Residual tumours}

In this case series, in 17 cases there was evident residual tumour on the first post-operative CT scan done after six weeks of surgery. Residual tumours were found in the region of the temporal and infratemporal fossa in four cases $(23.5$ per cent), in the

TABLE II

\begin{tabular}{lr}
\multicolumn{2}{c}{ STAGING OF THE 95 CASES } \\
\multicolumn{2}{c}{ INCLUDED IN THIS STUDY } \\
\hline Stage & Number of cases \\
\hline I & Not included \\
II & 10 \\
IIIa & 65 \\
IIIb & 10 \\
IVa & 7 \\
IVb & 3 \\
Total & 95 \\
\hline
\end{tabular}

TABLE III

RECURRENCES AND RESIDUAL TUMOURS IN DIFFERENT STAGES

\begin{tabular}{lccc}
\hline $\begin{array}{l}\text { Stage } \\
\text { of JNA }\end{array}$ & $\begin{array}{c}\text { No. of cases } \\
\text { operated }\end{array}$ & $\begin{array}{c}\text { Residual } \\
\text { tumour } n(\%)\end{array}$ & $\begin{array}{c}\text { Recurrence } \\
n(\%)\end{array}$ \\
\hline II & 10 & 0 & 0 \\
IIIa & 65 & $9(13.8)$ & $8(12)$ \\
IIIb & 10 & 0 & $2(20)$ \\
IVa & 7 & $5(71.4)$ & $3(43)$ \\
IVb & 3 & $3(100)$ & 0 \\
\hline
\end{tabular}

JNA $=$ juvenile nasopharyngeal angiofibroma 
TABLE IV

RESIDUAL AND RECURRENCE RATE OF JUVENILE NASOPHARYNGEAL ANGIOFIBROMA WITH INTRACRANIAL EXTENSIONS (AFTER 1ST STAGE SURGERY)

\begin{tabular}{|c|c|c|}
\hline Authors & $\begin{array}{l}\text { Residual or } \\
\text { recurrent/total } \\
(\%)\end{array}$ & Approach \\
\hline Danesi et $a l .^{6}$ (2000) & $3 / 14(21)$ & $\begin{array}{l}\text { Transfacial } \\
\text { (midline) }\end{array}$ \\
\hline Andrews et al. ${ }^{5}$ (1989) & $3 / 11(27)$ & $\begin{array}{l}\text { Lateral } \\
\text { infratemporal }\end{array}$ \\
\hline Close et al. ${ }^{7}$ (1989) & $1 / 6(17)$ & $\begin{array}{l}\text { Combined } \\
\text { frontotemperal } \\
\text { and lateral } \\
\text { infratemporal }\end{array}$ \\
\hline Jafek et $a l .^{8}$ (1979) & $8 / 15(53)$ & $\begin{array}{l}\text { Frontotemporal } \\
\text { craniotomy }+ \\
\text { transfacial }\end{array}$ \\
\hline $\begin{array}{l}\text { Achouche et al. }{ }^{9} \\
\text { (1992) }\end{array}$ & 10/17 (59) & $\begin{array}{l}\text { Transfacial } \pm \\
\text { neurosurgical }\end{array}$ \\
\hline Jones et al. ${ }^{10}$ (1986) & $6 / 12(50)$ & Transfacial \\
\hline $\begin{array}{l}\text { Deschler et al. } \\
\quad(1992)\end{array}$ & 6/7 (86) & $\begin{array}{l}\text { Transfacial } \pm \\
\text { frontal } \\
\text { craniotomy }\end{array}$ \\
\hline $\begin{array}{l}\text { Radkowski et al. }{ }^{12} \\
(1996)\end{array}$ & $1 / 3(33)$ & Transfacial \\
\hline Duvall et al. ${ }^{13}$ (1987) & $1 / 3(33)$ & $\begin{array}{l}\text { Midline } \pm \\
\text { neurosurgical }\end{array}$ \\
\hline
\end{tabular}

region of the sphenoid sinus, the base of the pterygoids, the clivus and the vidian canal in five cases (29.4 per cent), the medial aspect of the cavernous sinus in three cases (17.6 per cent) and large residual intracranial extensions were present in the remaining five cases (29.4 per cent). Since the majority of cases in this case series were operated on by a combined transpalatal and transmaxillary approach, the infratemporal fossa and temporal regions were additional sites where residual tumours were found. But tumour regrowth was not observed from these regions. Herman et $a l^{14}$ also observed that anterior approaches were associated with an increased incidence of residual tumours in the temporal and infratemporal region but tumour regrowth was not observed from these regions. Out of 13 cases in which recurrences occurred, in seven cases (54 per cent) there was evidence of residual tumours. In cases in which recurrences occurred, residual tumours were found in the region of the pterygoid fossa, sphenoid sinus, clivus, vidian canal, medial aspect of the cavernous sinus and the foramen ovale. Small evident residual tumours in these areas had regrown substantially by the time a second operation was performed in these seven cases. A postoperative CT scan should be performed after six weeks as an early scan may give a false impression of a residual tumour due to the pooling of secretions.

\section{Extensions into the pterygoid fossa}

Radkowski et al. ${ }^{12}$ observed that extensions of juvenile nasopharyngeal angiofibroma posterior to the pterygoid plates into the pterygoid muscles, a muscular bed similar to the infratemporal fossa, makes complete surgical excision difficult and increased risk of skull base erosion makes them prone to recurrences. Although the majority of angiofibroma cases usually extend laterally through the widened sphenopalatine foramen, sometimes angiofibroma may extend posterior to the pterygoid plates along the base of the skull involving the pterygoid fossa and may then extend laterally into the infratemporal fossa (retromaxillary spread) (Figure 2). This occurred in two cases in this present case series and both presented with residual and recurrent tumours (Figure 3). Juvenile nasopharyngeal angiofibroma extensions in the pterygoid fossa, a potential site of recurrent and residual tumours, ${ }^{12}$ were taken care of in this study by extending the limb of the transpalatal incision on the involved side into the retromaxillary region and if required, the medial pterygoid plate was removed to expose the extensions of the angiofibroma in the pterygoid fossa (Figures 4 and $5)$. The angiofibroma was then separated from surrounding soft tissues under direct vision. Since no major muscle is attached to the medial pterygoid plate so removal of the medial pterygoid plate produces less morbidity as compared to the lateral pterygoid plate, which is usually removed in lateral infratemporal approaches. Liu et al. ${ }^{15}$ also found a transpalatal approach combined with a labiogingival groove incision most appropriate to remove angiofibromas from the pterygoid fossa. Recurrences in their series were 16.7 per cent. Duvall et al. ${ }^{13}$ also recommended a combination of transantral, sublabial and transpalatal approaches, using a continuous palatobuccal (lazy S) incision around the maxillary tuberosity into the gingivobuccal sulcus to give a wide exposure to the pterygoid plates and the pterygomaxillary fossa.

\section{Intracranial extensions medial to the cavernous sinus}

Stage III and IV juvenile nasopharyngeal angiofibroma cases with involvement of the sphenoid sinus and extensions through the lateral wall of the sphenoid which were medial to the cavernous sinus were also prone to recurrent and residual tumours (23 per cent of cases). McGahan et al. ${ }^{16}$ advocated radiotherapy for extensions of juvenile nasopharyngeal angiofibroma which spread medial to the cavernous sinus and labelled them unresectable. Paris et al. ${ }^{17}$ (2001) used a transantral and lateral rhinotomy approach to remove such extensions and found it difficult to access the sphenoid sinus. Zhang et $a{ }^{18}{ }^{18}$ used lateral infratemporal approaches in stage III and IV juvenile nasopharyngeal angiofibroma and found that extensions of angiofibroma medial to the cavernous sinus were inaccessible by lateral approaches. Danesi et al. ${ }^{6}$ (2000) observed that tumours extending intracranially through an orbital fissure were lateral to the cavernous sinus and were accessible through either a lateral skull base or anterior approach like a transfacial one whereas tumours extending through the lateral wall of the sphenoid which were medial to the cavernous sinus were more readily removed through anterior approaches like a transfacial one with minimum morbidity. The sphenoid sinus and intracranial extensions of angiofibroma medial to the cavernous 


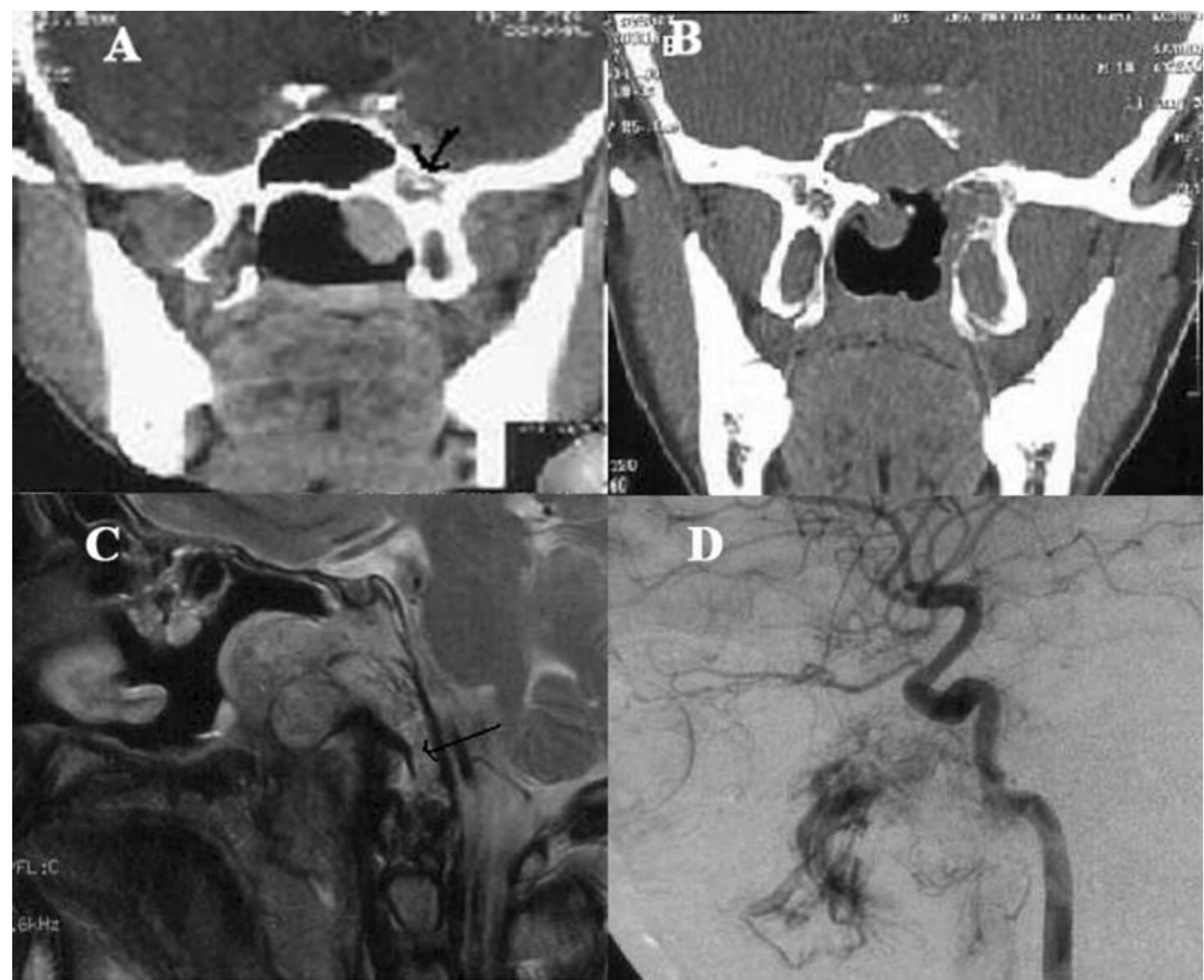

FIG. 1

(a) CT scan showing dilatation of the vidian canal, (b) a residual tumour in the region of the sphenoid sinus and medial to the cavernous sinus; the patient had a recurrence, (c) MRI showing erosion of the clivus by angiofibroma, marked with arrow, (d) feeders from the internal carotid artery as is clear from the tumour blush when contrast was injected through the internal carotid artery.

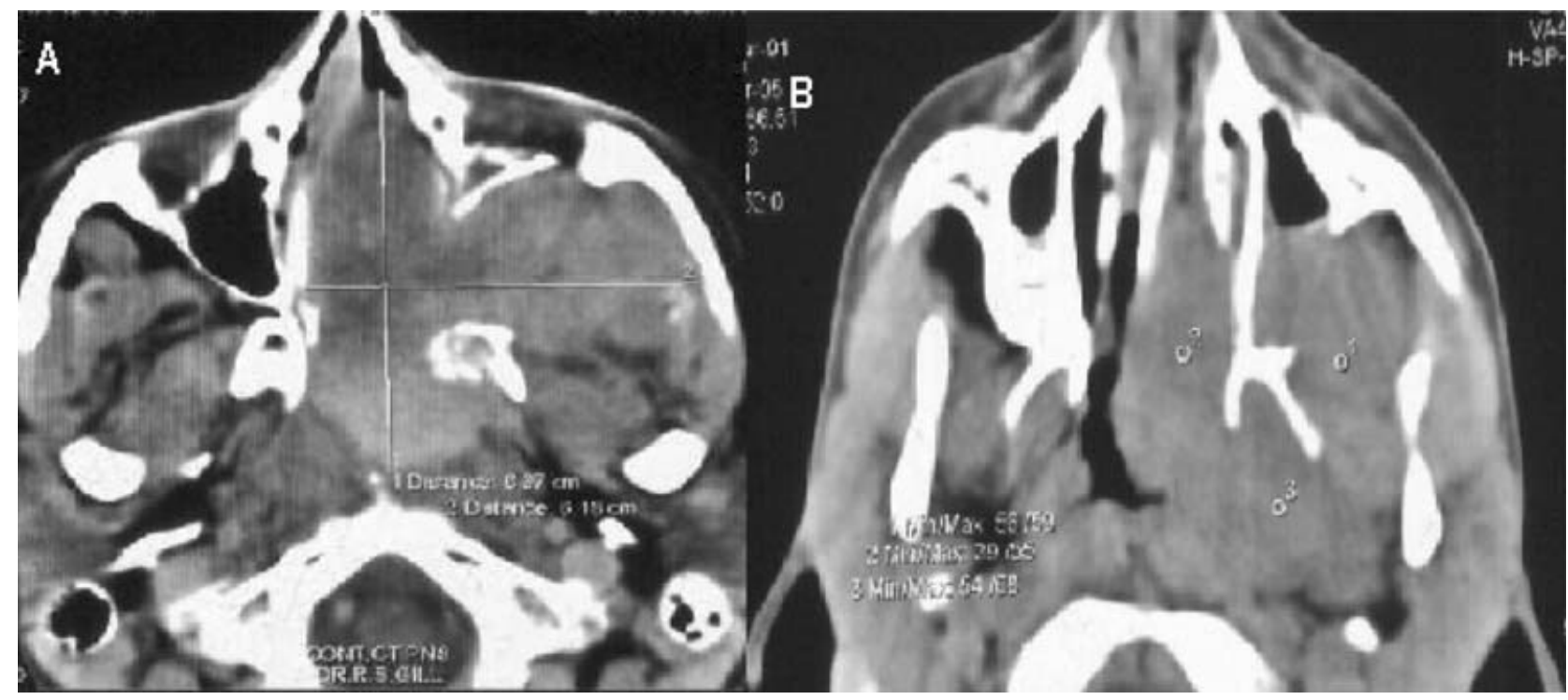

FIG. 2

Lateral spread of angiofibroma into the infratemporal fossa (a) through the widened sphenopalatine fossa (b) retromaxillary spread. 


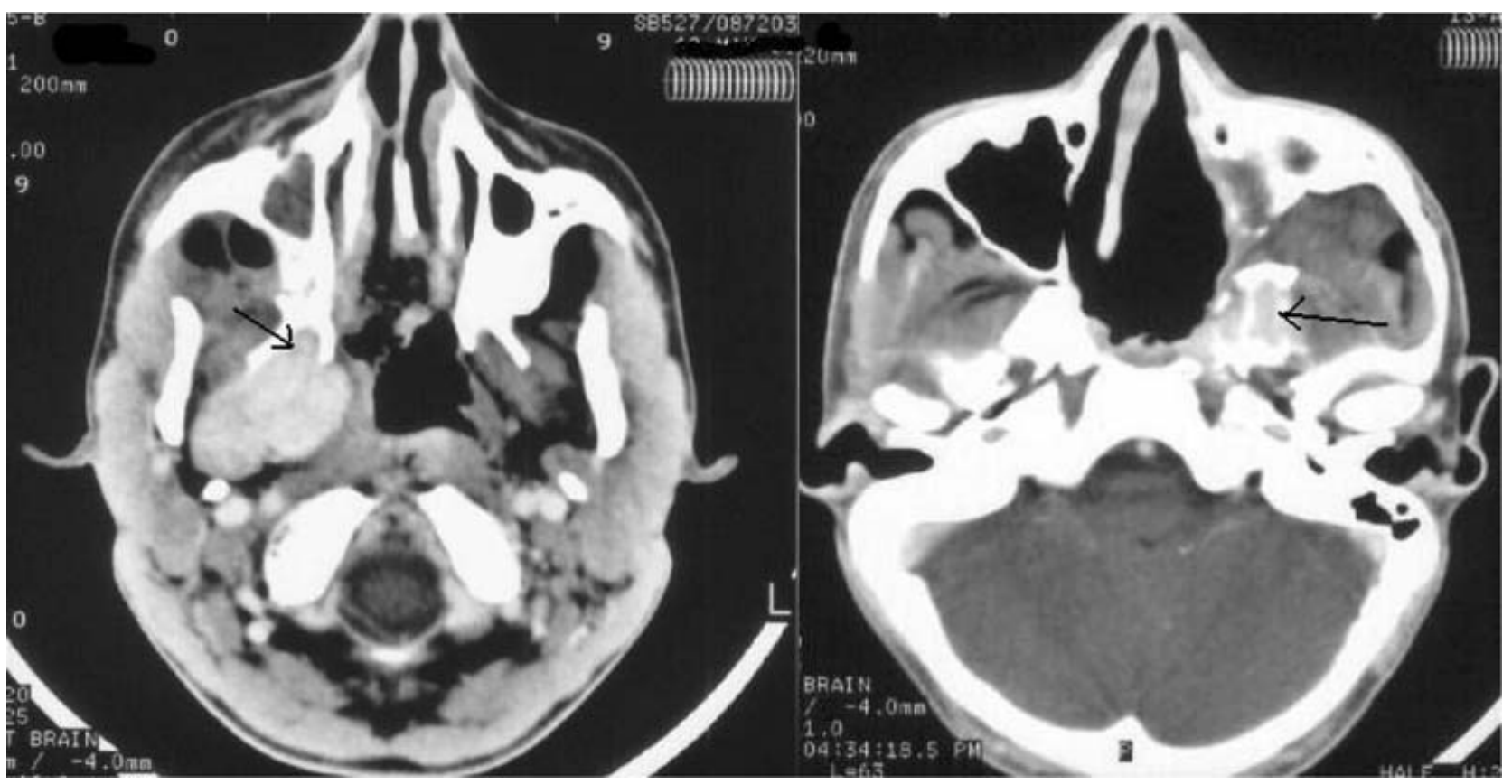

FIG. 3

Axial sections of CT scan showing residual tumour in the region of the pterygoid fossa.

sinus were easily accessible with a combined transpalatal and transmaxillary approach used in this case series. In spite of better exposure, in 23 per cent of cases of recurrence there was evident residual tumour in the sphenoid sinus eroding the lateral wall of the sphenoid and extending medial to the cavernous sinus. To remove the intracranial extensions of an angiofibroma through the lateral wall of the sphenoid that was medial to the cavernous sinus, tumours were displaced inferiorly from the roof of the sphenoid sinus. The plane between the tumour and the dura or thin bony remnant

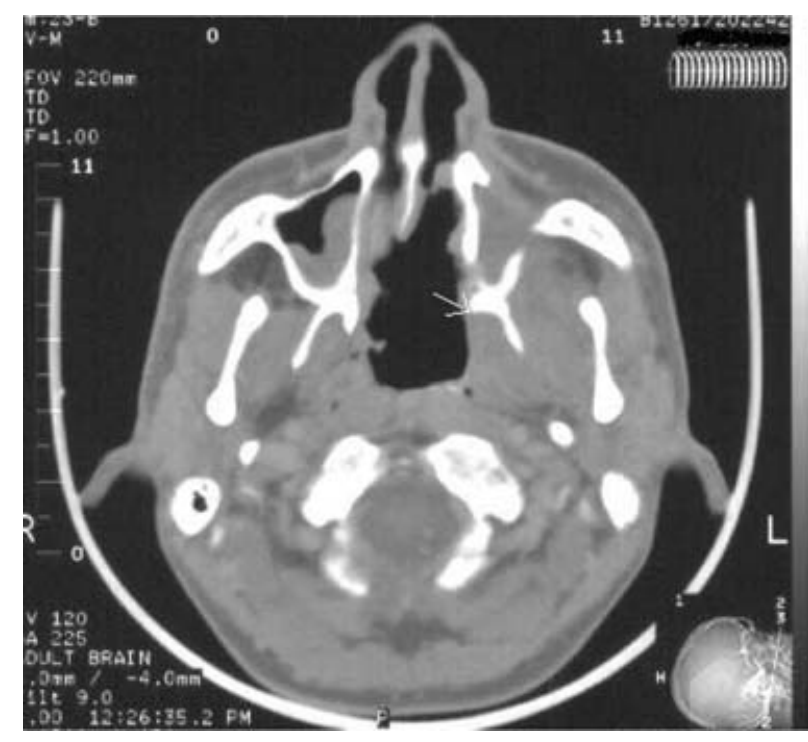

FIG. 4

Post-operative axial sections of CT scan showing removal of the medial pterygoid plate. were identified. The bony defect in the lateral wall of the sphenoid was widened. The tumour was then gently separated from the dura. Usually there was no infiltration of neural or vascular components. Venous bleeding usually encountered from the cavernous sinus dura was controlled with surgicel kept in place for a few minutes by cottonoid. We are now drilling the base of the sphenoid sinus to expose the base of the greater wing of the sphenoid followed by drilling in the area of the vidian canal which we feel can significantly decrease the incidence of recurrent and residual tumours.

\section{Age and feeders from the internal carotid artery}

A young age (95 per cent of recurrences occurred in patients below 18 years of age) and feeders from the internal carotid artery were other factors found to be associated with the aggressive behaviour of an angiofibroma and a higher incidence of recurrences. Definite feeders from the internal carotid artery or tumour blush after injecting contrast in the internal carotid artery were found in 10 cases. Five such cases had a recurrence of the angiofibroma (50 per cent). No correlation between the incidence of recurrence of an angiofibroma and pre-operative embolisation was found.

\section{Invasion of sphenoid diploe}

Lloyd et al. ${ }^{19}$ found two types of involvement of the sphenoid: simple pressure erosion (40 per cent) and deep invasion and expansion of the sphenoid (60 per cent). Ninety-three per cent of the recurrences occurred in the latter group. In this present case series, on retrospective analysis imaging the evidence of invasion of the sphenoid diploe through a widened pterygoid canal (Figure $6 \mathrm{a}$ and $\mathrm{b}$ ) was found in 

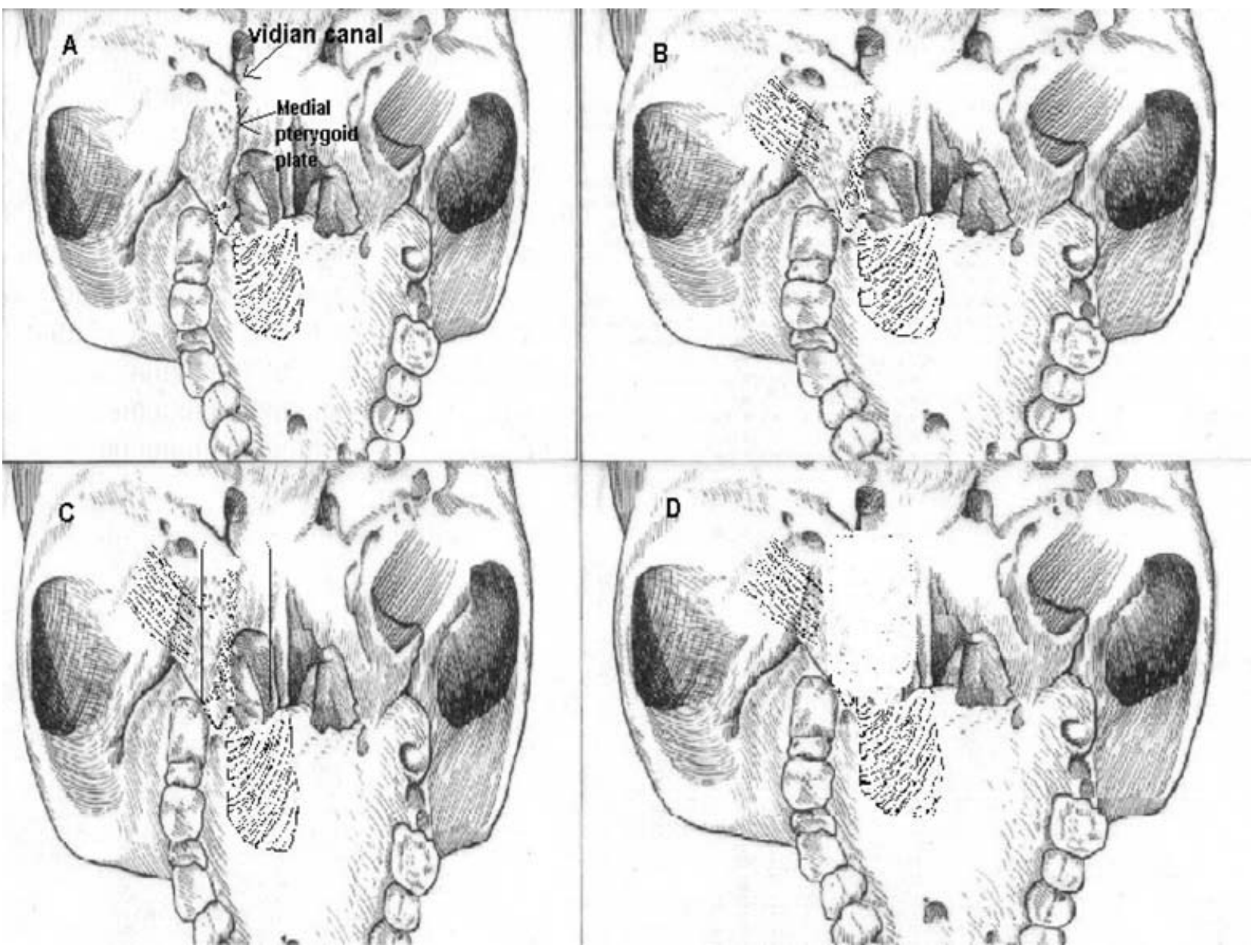

FIG. 5

Surgical technique (a) shows area of hard palate that was removed, (b) shows the removal of the medial pterygoid plate and exposure of the pterygoid fossa, also shows the tensor palati attached to the lateral pterygoid plate; (c) area of the vidian canal and cancellous bone of the sphenoid to be drilled, (d) area after drilling.

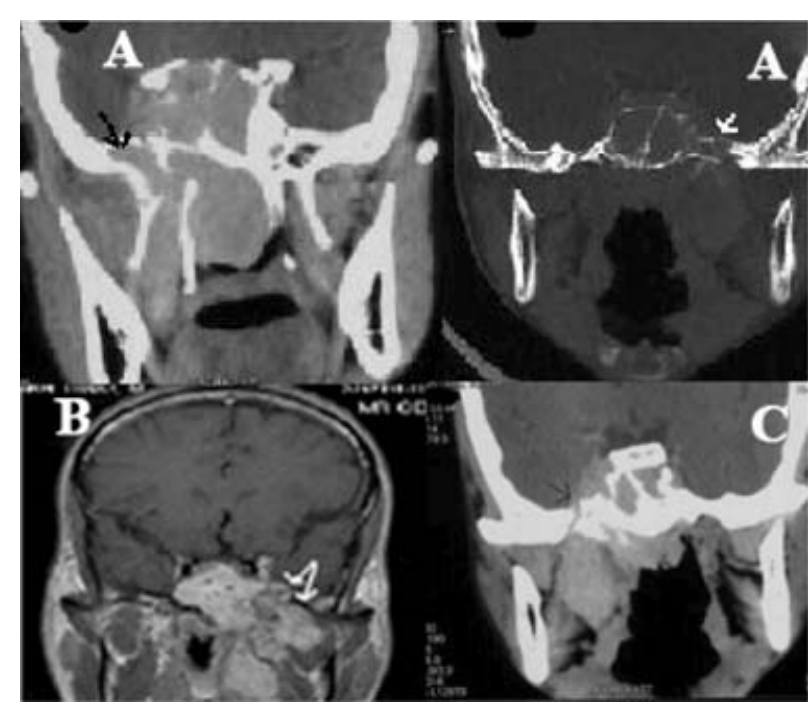

FIG. 6

(a) CT scans showing expansion of the greater wing of the sphenoid, (b) MRI showing infiltration of the marrow cavity of the greater wing of the sphenoid by the angiofibroma, (c) coronal sections of CT scan showing intracranial extensions of the angiofibroma through the foramen ovale.
84.6 per cent of cases (11 out of 13) of recurrences. Howard et al. ${ }^{20}$ also found that 93 per cent of recurrences occurred in patients with imaging evidence of invasion of the sphenoid diploe through a widened pterygoid canal. They also found that the mean number of recurrences was proportional to the degree of invasion of the greater wing of the sphenoid. Similarly, in the present case series the incidence of recurrence in stage IVa tumours was 43 per cent compared to 20 per cent in stage IIIb (Table III).

\section{Surgical approach}

In the present case series no correlation between surgical approaches and recurrences of angiofibroma was found. The majority of cases (96.9 per cent) in the present series were operated on by a combined transpalatal and transmaxillary approach by lazy $\mathrm{S}$ incision. In only 3.1 per cent (three cases) of cases in the present case series was a conservative lateral infratemporal approach (type D1 approach) used. Out of these three cases, in one case there was a large residual intracranial extension which was removed by staged frontotemporal craniotomy and in one case in spite of complete removal there was a recurrence. Retrospectively, when the MRI scan of this patient was reviewed there was imaging 
evidence of invasion of the sphenoid diploe (Figure 6b) which we feel should be drilled to avoid recurrences. A combined transpalatal and transmaxillary approach avoids sequelae like neuralgia, hearing loss, trismus and cosmetic defects that are associated with lateral approaches. ${ }^{6}$ Lateral approaches should be used only if either lateral extensions of the angiofibroma are very large, extending up to the temporal region, or if there are posterior extensions through the foramen ovale (Figure 6c). These extensions are not easily accessible by a combined transpalatal and transmaxillary approach and usually residual tumour remains if this approach is used. No cosmetic deformity, facial scar or facial asymmetry was produced with a combined transpalatal and transmaxillary approach as ethmoidectomy, nasal septal trauma, facial osteotomies and metal plate fixation, which are used in other anterior approaches and are usually considered to produce such defects, ${ }^{21}$ were avoided in this approach. This is very significant considering that the majority of juvenile nasopharyngeal angiofibroma patients are young and growth of the male craniofacial skeleton continues until at least 20 years of age and approximately 40 per cent of maxillary growth occurs after the age of 12 years. $^{21}$ Fagan et al. ${ }^{21}$ used facial translocation procedures along with infratemporal fossa approaches to remove angiofibromas and found a 37.5 per cent recurrence rate and patients usually suffered from cosmetic defects along with retarded facial growth. They observed that recurrences occurred in spite of adequate visualisation of the tumour and suggested lack of encapsulation and submucosal spread as risk factors of incomplete resection. This further justifies relatively conservative surgical approaches used by us as meticulous removal not wide exposure is required for not only complete removal of the angiofibroma but also to prevent recurrences.

- In the surgical management of juvenile nasopharyngeal angiofibroma the possibility of recurrences and residual tumours are always present

- This study was undertaken to predict the prognostic factors determining recurrence of juvenile nasopharyngeal angiofibromas and to find out the usual sites of these tumours

- Extensions into the pterygoid fossa and basisphenoid, erosion of the clivus, intracranial extensions medial to the cavernous sinus, invasion of the sphenoid diploe through a widened pterygoid canal, feeders from the internal carotid artery, a young age and residual tumours were risk factors found associated with recurrence of juvenile nasopharyngeal angiofibroma

\section{Drilling of the cancellous bone}

Howard et al. ${ }^{20}$ recommended that small lobules of angiofibromas remain in the cancellous bone of the sphenoid and pterygoid canal which should be regularly drilled to decrease the incidence of recurrences. For the last two years we have been drilling the cancellous bone in the region of the base of the pterygoids, vidian canal and clivus up to non bleeding bones. This has significantly decreased the incidence of recurrent and residual tumours in our institute. These areas are best approached, with minimum morbidity, by a combined transpalatal and transmaxillary approach, which was the preferred approach in the patients in our study group. Removal of the medial pterygoid plate is performed in order to approach the above mentioned areas, which produces less morbidity when compared to removal of the lateral pterygoid plate, as performed in other approaches, as the muscles of mastication are attached with the latter.

\section{Conclusions}

Extensions into the pterygoid fossa, clivus and basisphenoid, intracranial extensions medial to the cavernous sinus, evident residual tumours, invasion of the sphenoid diploe through a widened pterygoid canal, feeders from the internal carotid artery and young age were risk factors found associated with recurrence of juvenile nasopharyngeal angiofibroma. A combined transpalatal and transmaxillary approach with lazy $\mathrm{S}$ incision followed by nibbling of the medial pterygoid plate can expose the above mentioned areas with minimum morbidity. The majority of recurrences occurred in cases where there was imaging evidence of invasion and expansion of the sphenoid diploe through the pterygoid canal. Small lobules of angiofibromas remain in the cancellous bone of the sphenoid and pterygoid canal which should be regularly drilled to decrease the incidence of recurrences.

\section{References}

1 Batsakis JG. Vasoformative tumors. In: Batsakis JG, ed. Tumors of the Head and Neck, Clinical and Pathological Considerations, 2nd edn. Baltimore, London: Williams \& Wilkins Co, 1979;296-300

2 Neel HB 3rd, Whicker JH, Devine KD, Weiland LH. Juvenile angiofibroma: review of 120 cases. Am J Surg 1973; 126:547-56

3 Lafargue B. Considerations on the nasopharyngeal angiofibroma anatomica-private clinic [in French]. Rev Laryngol 1947;68:436-65, 514-39

4 Fisch U. The infratemporal fossa approach for nasopharyngeal tumors. Laryngoscope 1983;93:36-44

5 Andrews JC, Fisch U, Valavanis A, Aeppli U, Makek MS. The surgical management of extensive nasopharyngeal angiofibromas with the infratemporal fossa approach. Laryngoscope 1989;99:429-37

6 Danesi G, Panizza B, Mazzoni A, Calabrese V. Anterior approaches in juvenile nasopharyngeal angiofibromas with intracranial extension. Otolaryngol Head Neck Surg 2000:122:277-83

7 Close LG, Schaefer SD, Mickey BE, Manning SC. Surgical management of nasopharyngeal angiofibroma involving the cavernous sinus. Arch Otolaryngol Head Neck Surg 1989; 115:1091-5

8 Jafek BW, Krekorian EA, Kirsch WM, Wood RP. Juvenile nasopharyngeal angiofibroma: management of intracranial extension. Head Neck Surg 1979;2:119-28

9 Achouche J, Laccourreye O, de Gaudemar I, George B, Merland JJ, Tran Ba, Huy P. Intra- and extracranial 
nasopharyngeal fibroma. Contribution of imaging and study of local failure. Report on 34 patients. Ann Otolaryngol Chir Cervicofac. 1992;109:223-30

10 Jones GC, DeSanto LW, Bremer JW, Neel HB 3rd. Juvenile angiofibromas. Behavior and treatment of extensive and residual tumors. Arch Otolaryngol Head Neck Surg 1986; 112:1191-3

11 Deschler DG, Kaplan MJ, Boles R. Treatment of large juvenile nasopharyngeal angiofibroma. Otolaryngol Head Neck Surg 1992;106:278-84

12 Radkowski D, McGill T, Healy GB, Ohlms L, Jones DT. Angiofibroma. Changes in staging and treatment. Arch Otolaryngol Head Neck Surg 1996;122:122-9

13 Duvall AJ, Moreano DE. Juvenile nasopharyngeal angiofibroma: diagnosis and treatment. Otolaryngol Head Neck Surg 1987:97:534-540

14 Herman P, Lot G, Chapot R, Salvan D, Huy PT. Longterm follow-up of juvenile nasopharyngeal angiofibromas: analysis of recurrences. Laryngoscope 1999;109:140-7

15 Liu L, Wang R, Huang D, Han D, Ferguson EJ, Shi H et al. Analysis of intra-operative bleeding and recurrence of juvenile nasopharyngeal angiofibromas. Clin Otolaryngol Allied Sci 2002;27:536-40

16 McGahan RA, Durrance FY, Parke RB Jr, Easley JD, Chou JL. The treatment of advanced juvenile nasopharyngeal angiofibromas. Int J Radiat Oncol Biol Phys 1989;17: 1067-72

17 Paris J, Guelfucci B, Moulin G, Zanaret M, Triglia JM. Diagnosis and treatment of juvenile nasopharyngeal angiofibroma. Eur Arch Otorhinolaryngol 2001;258 $120-4$

18 Zhang M, Garvis W, Linder T, Fisch U. Update on the infratemporal fossa approaches to nasopharyngeal angiofibroma. Laryngoscope 1998;108:1717-23

19 Lloyd G, Howard D, Phelps P, Cheesman A. Juvenile angiofibroma: the lessons of 20 years of modern imaging. J Laryngol Otol 1999;113:127-34

20 Howard DJ, Lloyd G, Lund V. Recurrence and its avoidance in juvenile angiofibroma. Laryngoscope 2001;111:1509-11

21 Fagan JJ, Snyderman CH, Carrau RL, Janecka IP. Nasopharyngeal angiofibromas: selecting a surgical approach. Head Neck 1997;19:391-9

Address for correspondence:

Dr Rajan Syal,

Neuro-otology Unit,

Department of Neuro-surgery,

Sanjay Gandhi Post Graduate Institute of Medical Sciences, Raibareily Road,

Lucknow (UP) - 226014 India.

E-mail: rajans@sgpgi.ac.in

Dr R Syal takes responsibility for the integrity of the content of the paper.

Competing interests: None declared 